\title{
AS TEORIAS FEMINISTAS E A EVOLUÇÃO DAS RELAÇÕES DE GÊNERO NA SOCIEDADE
}

\author{
FEMINIST THEORIES OF EVOLUTION AND GENDER \\ RELATIONS IN SOCIETY
}

\author{
Sandra Puhl dos Santos*
}

\begin{abstract}
RESUMO
A trajetória de resistência e luta das mulheres consolidou a igualdade de direitos e continua ampliando, dia a dia, o movimento pela igualdade na vida, nos novos espaços que vão sendo conquistados. A história demonstra que as primeiras conquistas específicas das mulheres se deram não só por meio da luta pela igualdade legal e contra as restrições dos seus direitos, mas também por meio da luta pela eliminação das barreiras que lhes impediam o desenvolvimento como pessoas. $\mathrm{Na}$ sociedade em que o desenvolvimento humano é preterido em função dos interesses econômicos submetidos à cultura patriarcal, concretiza-se uma contradição: homens e mulheres são considerados cidadãos e cidadãs, mas a vivência de sua plena cidadania dependerá de sua condição de gênero e de classe social. Este artigo objetiva promover uma reflexão acerca da evolução da mulher no contexto organizacional sob o enfoque das diversas teorias feministas, que possibilitaram compreender as diferentes formas de construção da identidade social e individual da mulher e refletir sobre as relações de gênero: como se criam, se transformam ou se mantêm na sociedade.
\end{abstract}

Palavras-chave: Teorias feministas. Relações de gênero. Mulher. Mercado de trabalho.

\begin{abstract}
The path of resistance and struggle of women consolidated equal rights and continues to expand the movement for equality in life in the new spaces that are being conquered. History shows that the first women's specific achievements occurred not only through the struggle for legal equality and against restrictions of their rights, but also through the struggle to eliminate the obstacles that prevented them to develop as human beings. In a society in which human development is deprecated in favor of economic interests submitted to a patriarchal culture, a contradiction is observed: men and women are considered citizens: but their full citizenship depends on their gender and their social class. This article aims to
\end{abstract}

\footnotetext{
" Mestranda em Desenvolvimento pela Universidade Regional do Noroeste do Estado do Rio Grande do Sul (Unijuí) e graduada em Ciências Contábeis pela mesma instituição. Email: sandrapuhl@hotmail.com
} 
promote a reflection on the evolution of women in the organizational context under the focus of several feminist theories, which enabled to understand the different forms of social construction of identity and women's individual and reflect on gender relations: how they are generated, how they are transformed or whether they are maintained by society.

Keywords: Feminist theories. Gender relations. Women. Labor market.

\section{Introdução}

A sociedade contemporânea vivencia um cenário de transformações que afetam diretamente o sistema econômico e social. As mudanças ocorridas nas últimas décadas modificaram a vida das pessoas e organizações e estabeleceram uma nova forma de relacionamento entre os seres humanos. Dentre as muitas mudanças que influenciaram diretamente o ambiente organizacional, destacam-se a globalização, as mudanças tecnológicas, a diversidade cultural da mão de obra, as mudanças nas exigências dos clientes, a introdução de modelos de gestão cada vez mais sofisticados, a nova concepção do trabalho e as diferentes expectativas da sociedade.

As relações de trabalho ganharam novos significados e complexidades a partir da inserção feminina no espaço organizacional. No decorrer da história, observa-se que as mulheres conquistaram alguns direitos, mudaram seu modo de pensar e agir, deixaram de ser submissas ao homem para tentar ficar em condição de igualdade com ele.

Pesquisas mostram que a força do trabalho feminino está cada vez mais presente na produção econômica e, progressivamente, a mulher vem assumindo posição de destaque no mercado de trabalho, mas a discriminação originada pela desigualdade é subjacente mesmo com aplicações das normas implementadas contra essa forma de segregação. O reflexo cultural e social como fator determinante da acomodação feminina durante gerações e a capacidade criativa do setor empresarial em burlar os preceitos da legislação de proteção à mulher não viabilizaram as mudanças necessárias.

A inserção da mão de obra feminina no mercado de trabalho desperta a discussão de questões que envolvem a interação entre homens e mulheres nesse ambiente. Apesar do discurso de igualdade de condições e oportunidades, há evidências de que existem desigualdades na participação masculina e feminina no mercado de trabalho, seja em relação aos níveis salariais, à possibilidade de crescimento na carreira ou às oportunidades de exercer determinadas funções. Nesse contexto, a teoria das relações de gênero auxilia a compreensão dessas questões, bem como a discussão do processo de construção da identidade da mulher na conjuntura organizacional.

Nas últimas décadas, tem ocorrido um grande avanço nas pesquisas sobre gênero e o estudo de questões que envolvem a evolução das mulheres nas organizações (CALÁS; SMIRCICH, 1999; BUTLER, 2003; CAPELLE, 2004), a grande maioria originada a partir do movimento feminista, época em que as questões relacionadas a gênero se tornaram mais evidentes e ganharam novos significados.

Assim, os estudos que contemplam a discussão sobre o tema "Relações de Gênero" apresentam uma variedade de direções. $\mathrm{O}$ fato pode ser entendido pela análise da evolução dos conceitos de gênero conforme a influência da época. Capelle (2004) argumenta que as abordagens mais remotas sobre o gênero consideravam as características biológicas de cada sexo, atribuindo a esse fato as desigualdades entre eles.

Calás e Smircich (1999) apresentam o conceito de gênero com base nas teorias feministas que resumem diversas abordagens feministas aos estudos organizacionais, buscando descrever como cada escola trata do tema de modo diferente, propondo também diferentes alternativas de análise.

Entretanto, apesar de todo o avanço alcançado ainda se percebe a presença da dominação masculina em quase todos os campos das relações sociais. Embora as abordagens recentes sobre os estudos que contemplam a mulher nas organizações tenham auferido considerável espaço na literatura e meio acadêmico, o tema ainda é predominantemente masculino. A teoria organizacional tem se caracterizado por 
uma "literatura escrita por homens, para os homens e sobre os homens" (CALÁS; SMIRCICH, 1999, p. 281).

Sardenberg (2004, p. 24) compartilha dessa ideia ao afirmar que feministas de todas as épocas "criticaram as pretensões dos grandes esquemas teóricos, as teorias gerais, argumentando que as supostas afirmativas universais sempre se mostraram parciais ou triviais." Assim, argumentavam que o conhecimento científico foi produzido a partir de uma perspectiva masculina, de uma visão androcêntrica, portanto era parcial, incompleto e questionável.

Além disso, as metateorias não eram capazes de interpretar a realidade como um todo, pois, ao contrário da imparcialidade que aclamavam, os cientistas eram homens que falavam a partir de vivências diferenciadas das experiências das mulheres.

Nesse contexto, faz-se necessário compreender essas mudanças a partir de estudos bibliográficos que possam contribuir para a produção de um conhecimento crítico, promovendo uma reflexão acerca da evolução da mulher no âmbito organizacional e das relações de gênero, sob o enfoque das teorias feministas.

Para a elaboração deste estudo, optou-se pela pesquisa bibliográfica, tomando por base material já elaborado, constituído principalmente de livros, artigos científicos publicados em periódicos e anais de eventos, e também documentos disponibilizados em meio eletrônico, pertinentes à temática abordada. Para embasamento teórico, foram citados alguns estudiosos do tema: Beauvoir, 1970; Tong, 1998; Calas e Smircich, 1999; Calil, 2000; Butler, 2003; Capelle, 2004.

\section{Teorias feministas}

Apesar de sua diversidade, a maior parte das teorias feministas tem alguns pressupostos comuns, notadamente o reconhecimento da dominação masculina nos arranjos sociais e o desejo de mudanças nessa forma de dominação.

Outro ponto a ser observado nas teorias feministas é a diferença entre sexo e gênero. Sexo é biologicamente definido, relacionado às diferenças morfológicas entre homens e mulheres. Quanto ao gênero, é "sociologicamente construído, um produto da socialização e vivência" (CALÁS; SMIRCICH, 1999, p. 276).
As diversas abordagens do pensamento feminista se conectam com as teorias e as práticas organizacionais, enfocando aspectos específicos, ou questões centrais, e ignorando outros.

Calás e Smircich (1999) classificam a teoria feminista em sete diferentes abordagens: liberal, radical, psicanalítica, marxista, socialista, pós-estruturalista/pós-moderna e multicultural (terceiromundista ou pós-colonialista). Cada abordagem oferece formas alternativas para o enfoque da desigualdade de gênero, enquadrando o problema de forma diferenciada, propondo diferentes caminhos de ação como solução.

A primeira escola analisada é a da teoria feminista liberal, originada dos ideais políticos liberais de igualdade, liberdade e fraternidade, durante os séculos XVII e XVIII. As mulheres não votavam e não podiam ter propriedades em seu nome. Com a transição de uma forma de produção econômica centrada no lar para uma economia industrial, elas foram gradativamente se tornando isoladas e dependentes economicamente. Assim, a maior preocupação da abordagem liberal era demonstrar que as mulheres eram tão humanas quanto os homens. O tema central abordado não era a eliminação da desigualdade sexual, mas a busca da equidade sexual/justiça de gênero.

Outra abordagem apresentada pelas autoras é a teoria radical, a qual surgiu na década de 1960, com os movimentos feministas contemporâneos. A fundamentação dessa abordagem consiste na subordinação feminina à dominação masculina, ditada pelo sistema de gênero, construído socialmente a partir de diferenças biológicas. Propõe que a sociedade ideal seria aquela livre de distinções de gênero ou de sexo.

Calás e Smircich (1999) destacam que as feministas radicais descobriram e colocaram em prática formas organizacionais que refletem valores feministas, tais como igualdade, comunidade, participação e integração de forma e conteúdo. Eram reativas, procurando rejeitar todos os elementos associados à forma masculina de poder. As autoras ainda chamam a atenção para o fato de que os estudos das organizações feministas raramente têm aparecido na literatura dominante sobre estudos organizacionais.

Nessa perspectiva, sob a inspiração do feminismo radical, alguns estudiosos estão revendo não apenas formas e práticas organizacionais, mas formas e práticas de teorização organizacional, 
centrada na mulher, baseada em suas vidas e experiências, para criar revisões feministas de conceitos organizacionais básicos, tais como trabalho, carreira e gestão.

A principal expoente do feminismo radical foi Simone de Beauvoir. Para essa autora, a mulher é o outro, tendo em vista que ela é definida tendo o homem como parâmetro: "a mulher determina-se e diferencia-se em relação ao homem e não este em relação a ela" (BEAUVOIR, 1970, p.10).

Beauvoir (1970) foi uma teórica da Igualdade que tratou a questão sexo/gênero visualizando o conceito de sexo como um dado biológico e o de gênero como construto social. Sua obra foi um marco para o feminismo, pois tratou da "questão de gênero, antes mesmo de termos um termo para identificar esse fenômeno da construção social das diferenças e identidades sexuais" (SARDENBERG, 2004, p.17).

A seguinte escola abordada é a feminista psicanalítica, originária da psicanálise freudiana. Essa teoria considera que a natureza humana se desenvolve tanto biológica quanto psicologicamente, e que os indivíduos criam sua identidade sexual como parte de seu desenvolvimento psicossexual. $\mathrm{O}$ gênero seria a estrutura de um sistema social de dominação masculina. A base para a desigualdade entre os gêneros estaria enraizada numa série de experiências na infância, as quais resultariam não apenas na visão dos homens enquanto sexo masculino e das mulheres enquanto sexo feminino, mas também no ponto de vista das sociedades patriarcais de que o masculino é melhor do que o feminino (TONG, 1998).

O feminismo psicanalítico, como é aplicado aos estudos organizacionais, considera as consequências do desenvolvimento psicossexual feminino diferenciado em seus papéis na organização e na gerência. Pesquisas recentes têm tratado as diferenças das mulheres não como um problema, mas como uma vantagem. A influência de psicólogos e psicanalistas feministas, assim como a dos feminismos radicais culturais levaram a trabalhos que destacam que os diferentes traços de caráter e a socialização diferenciada dos papeis sexuais não são deficiências a serem superadas, mas vantagens para a efetividade corporativa (CALÁS; SMIRCICH, 1999).

Já a teoria marxista surgiu baseada na crítica marxista da sociedade capitalista e no liberalismo político. Marx (2003) afirma que não é a consciên- cia dos homens que determina sua existência, mas sua existência social que determina sua consciência. De acordo com essa abordagem, a natureza humana concebe gênero e identidade de gênero como definições estruturais, históricas e materiais. Nessa perspectiva, Calás e Smircich (1999) asseguram que gênero é classe; os gêneros são, portanto, categorias sociais caracterizadas por relações de dominação e opressão, funcionando como um determinante de padrões estruturais. Em suma, o pensamento feminista marxista analisa a dinâmica produtiva e reprodutiva das dinâmicas de gênero na organização capitalista e patriarcal da economia e da sociedade.

Em resposta à insatisfação com o pensamento marxista, segundo o qual a opressão feminina seria menos importante do que a opressão do trabalhador, surge a teoria feminista socialista, na qual o gênero é instituído mediante encontros de sexo, raça, ideologia e opressão, sob os sistemas capitalistas e patriarcal. Assim, o término da segregação ocorreria com a extinção das classes e a transformação das relações sociais.

Na mesma visão, Jaggar (1983) apud Calás e Smircich (1999) afirma que a divisão social de trabalho é uma característica básica da sociedade capitalista que afeta tanto os homens quanto as mulheres. Para o referido autor, o feminismo socialista defende uma sociedade em que masculinidade e feminilidade são socialmente irrelevantes e não existem homens e mulheres como são concebidos atualmente.

Em outro direcionamento, Calás e Smircich (1999) apresentam a teoria estruturalista/pós-moderna, situada nas críticas pós-estruturalistas francesas contemporâneas do conhecimento e da identidade. Retira do centro o sujeito racional do humanismo: subjetividade e consciência são efeitos discursivos. De acordo com essa abordagem, sexo e gênero são práticas discursivas que constituem subjetividades específicas por meio de poder e resistência na materialidade dos corpos humanos.

Em geral, as teorias feministas pós-modernas/ pós-estruturalistas oferecem uma visão mais pluralista de engajamentos políticos, em que gênero se torna apenas um argumento entre outros. Também oferece visões mais complexas da localização social e das estruturas de opressão. Já a análise desconstrutivista e genealógica prevê uma estratégia importante para demonstrar os limites do discurso organizacional e 
as estruturas desses limites, que são frequentemente baseadas em distinções de gênero.

Por fim, as autoras abordam a teoria terceiro-mundista ou pós-colonial, na qual se critica a generalização das questões de gênero apontadas pelas feministas do Primeiro Mundo, cujo caráter totalitário considera as outras mulheres como seres invisíveis ou quase humanos. Essa teoria critica também as relações de dominação do Primeiro Mundo sobre os outros países, admitidas pela divulgação de um conhecimento tido como absoluto e inquestionável.

Enfim, as teorias feministas possibilitaram compreender as diferentes formas de construção da identidade social e individual da mulher, mas também refletir sobre as relações de gênero: como se criam, se transformam ou se mantêm os padrões de gênero na sociedade.

\section{A evolução das mulheres numa perspectiva histórica}

Os valores masculinos se sobrepõem aos femininos há cerca de dez mil anos; de geração em geração, as mulheres vêm sendo vítimas de preconceito através da história da humanidade.

No Cristianismo, o princípio bíblico da criação já demonstra a fragilidade da mulher diante do homem, em Gênesis (GÊNESIS, 2: 21-22):

Então Deus fez cair um torpor sobre o homem, e ele dormiu. Tomou uma de suas costelas e fez crescer carne em seu lugar. Depois da costela que tirou do homem, Deus modelou uma mulher e a trouxe ao homem.

Gênesis relata ainda que, após a criação, a mulher foi tentada pela serpente e sucumbiu, deu de comer a Adão o fruto proibido. Então, Deus disse à mulher: "Multiplicarei grandemente a dor da tua concepção; em dor darás à luz filhos; e o teu desejo será para o teu marido, e ele te dominará" (GÊNESIS, 3: 16). Assim, por causa da "transgressão da mulher", Adão e Eva foram expulsos do Paraíso.

Na simbologia da criação, percebe-se o surgimento do ser humano feminino e a criação do ser humano masculino, no intuito de identificar gêneros.
Figura 1 - Lucas Cranach; O Velho. Adão e Eva (1531)

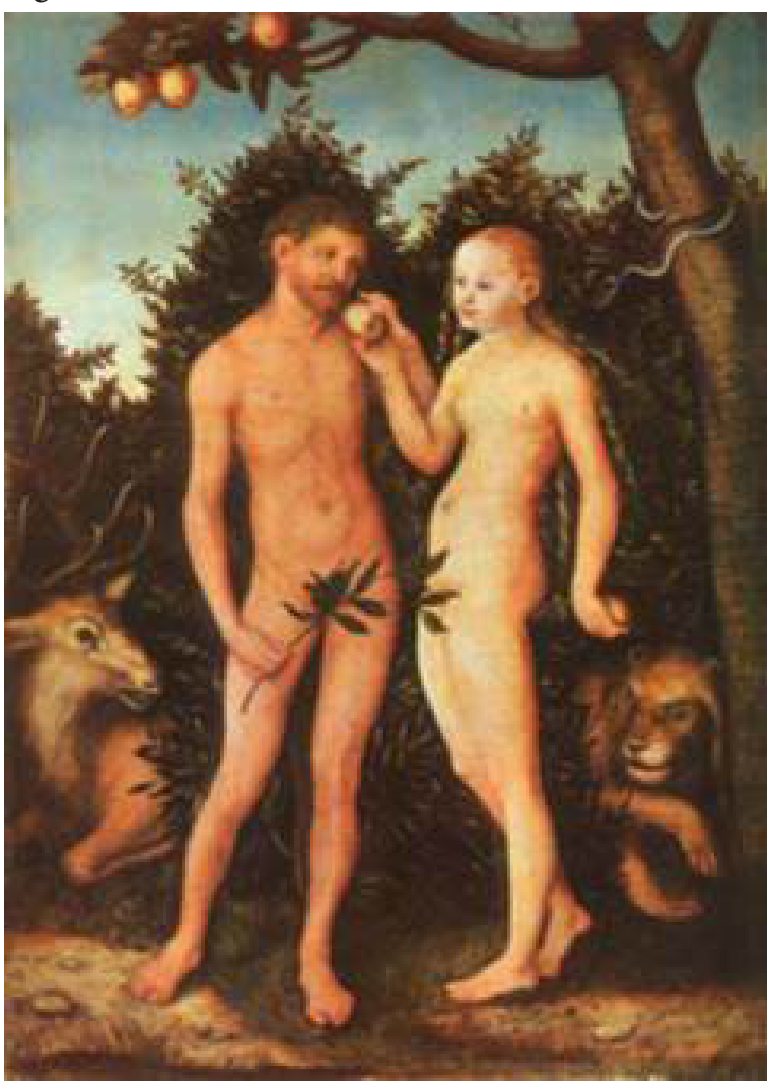

Fonte: Staatliche Museen, Berlim

Já no Novo Testamento, na doutrina bíblica, Jesus Cristo tenta resgatar os valores da mulher, elevando-a a um nível diferenciado, tentando restituir sua dignidade. Jesus quebrou vários tabus construídos ao longo da história, ao deixar, por exemplo, ungir-lhe os pés uma mulher considerada pecadora, conforme se lê no Evangelho de São Lucas (LUCAS, 7: 36-50). Beneficiou mulheres, como a sogra de Pedro, curando-a de febre (LUCAS, 4: 3839); e, no Evangelho de Mateus, ressuscitou a filha de Jairo, oficial romano (MATEUS, 9: 18-29).

Apesar disso, a Igreja ainda exercia forte pressão em adestrar a sexualidade feminina, dando autonomia ao homem, conforme pode ser lido na primeira carta de Paulo de Tarso a Timóteo (I TIMÓTEO, 9: 11-14):

Quanto às mulheres, que elas tenham roupas decentes, se enfeitem com pudor e modéstia (...). Durante a instrução a mulher conserve o silêncio, com toda submissão. Eu não permito que a mulher ensine ou domine o homem. Que ela conserve, pois, o silêncio. Porque primeiro foi formado Adão, 
depois Eva. E não foi Adão que foi seduzido, mas a mulher que, seduzida, caiu em transgressão.

No entendimento de Vieira (2004), o próprio processo de evangelização, após a morte de Jesus Cristo, fez com que Paulo de Tarso amadurecesse e, exercitando o postulado da doutrina cristã, passasse a reconhecer o valor feminino, documentando-o em suas cartas, por exemplo, quando escreve ao povo de Coríntios (I CORINTIOS, 11: 12): "Em Cristo não há mulher sem homem e nem homem sem mulher; como é verdade que a mulher procede do homem, é também verdade que o homem procede da mulher e tudo vem de Deus". Assim, através da ascensão da doutrina cristã, a mulher começou a ter reconhecido o seu valor de direito à igualdade com os homens.

Nos estudos mitológicos da história da humanidade, há cerca de vinte mil anos, se fazia referência ao feminismo, à mulher como deusa, identificada como Terra, "de onde tudo saia e para onde tudo voltava", daí a existência dos seres. As mais antigas imagens sagradas são de mulheres. Estas governavam as sociedades pela "linhagem feminina". A origem de tal poder se baseava no fato de que tinham o dom de gerar a vida, supunham que pariam deuses, ou seja, o poder econômico era o poder de gerar (MURARO; BOFF, 2002).

Para esses autores, essa foi a época em que as atividades humanas viviam em equilíbrio, tanto entre os humanos como com a natureza. O sentido da vida era exclusivamente para atender às necessidades básicas. Não havia competição ou cobiça, nem tampouco guerras. As mulheres não utilizavam força física para exercer o poder, faziam isso através de persuasão e consenso. Com o passar dos anos, no entanto, a exuberância da natureza foi diminuindo, criando a necessidade de caçar grandes animais, iniciando-se assim uma nova cultura, baseada em modelos de dominação e autoritarismo.

Desde então, os mais fortes passaram a dominar os mais fracos, o povo começa a lutar por seu território e iniciam-se as batalhas pela supremacia utilizando a força física. As guerras passam a ser rotina, bem como a invasão de terras, segundo expressam Muraro e Boff (2002, p.174):

Os princípios feminino e masculino, que governavam juntos o mundo até então, se dividem: a mulher fica reclusa no domínio da casa - do privado
- e o homem assume o domínio público. Agora é a lei do mais forte que consolida o seu poder. Um poder que não é mais um serviço e sim um privilégio. Agora a relação que predomina é a do senhor e do escravo. O homem domina e a mulher é a dominada.

Na Idade Clássica, a vida das mulheres gregas consistia em doar-se ao máximo a seus maridos e filhos e abdicar quase que totalmente de seus interesses e vontades. Quando os casamentos tinham problemas, as leis repreendiam severamente a mulher, pois esperavam destas a castidade. Demóstenes (384 a.C. - 322 a.C.), orador e político grego de Atenas, em seus discursos afirmava: "Temos cortesãs para nos dar prazer; temos concubinas para com elas coabitarmos diariamente; temos esposas com o propósito de termos filhos legítimos e de termos uma guardiã fiel de tudo o que se refere à casa." Essa realidade deixa transparecer a desvalorização da mulher.

Já as mulheres romanas tinham como centro de atuação o âmbito doméstico. As suas funções consistiam em rezar com o marido e os filhos, organizar a casa e preparar-se para recepcionar o marido. A educação era privilégio de poucos, aos meninos de famílias abastadas ensinava-se o latim, o grego, cálculos, literatura e a retórica. As meninas aprendiam os deveres domésticos com suas mães, e as famílias humildes raramente tinham acesso à alfabetização.

$\mathrm{Na}$ Idade Média, as ideias e conceitos eram elaborados pelos eclesiásticos. As mulheres eram consideradas pelo clero como seres suscetíveis às tentações demoníacas, por isso deviam ficar sob a tutela do marido. Afinal, todas as mulheres descendiam de Eva, a culpada pela queda do gênero humano. Eva concentrava em si todos os vícios tidos como femininos: a luxúria, a gula, a sensualidade e a sexualidade. Dessa forma, a maior parte das autoridades eclesiásticas desse período via a mulher como portadora e disseminadora do mal.

A partir do século XI, com a instituição do casamento pela Igreja, a maternidade e o papel dado à esposa passaram a serem exaltados. Criou-se uma forma de salvação feminina a partir basicamente de três modelos: Eva (a pecadora), Maria (o modelo de perfeição e santidade) e Maria Madalena (a pecadora arrependida). No casamento a mulher estaria restrita a um só parceiro, que tinha a função de dominá-la, de educá-la e de fazer com que tivesse uma vida pura e casta. 
Maria foi a redentora de Eva, pois veio ao mundo com a missão de liberá-la da maldição da queda. Desenvolveu-se então a ideia de Maria como a mãe da humanidade, de todos os homens e mulheres que viviam na graça de Deus. O culto a Maria se baseava em quatro pilares: a maternidade divina, a virgindade, a imaculada concepção e a assunção. Por isso, as mulheres eram encorajadas a se manterem castas até o casamento, se a sua opção fosse o matrimônio. Porém, a melhor forma de seguir o exemplo de Maria era permanecer virgem e tornar-se esposa de Cristo, com base na ideia recorrente de que Maria era "irmã, esposa e serva do Senhor". Eva simbolizava as mulheres reais, e Maria um ideal de santidade que deveria ser seguido por todas as mulheres para alcançarem a graça divina a caminho da salvação. Já com Maria Madalena se estende a possibilidade de salvação a todos que caíssem no erro, mas fossem capazes de se arrepender (PRATAS, 2011).

Figura 2 - Lucas Cranach; O Velho. A Virgem e o Menino (1525-1530)

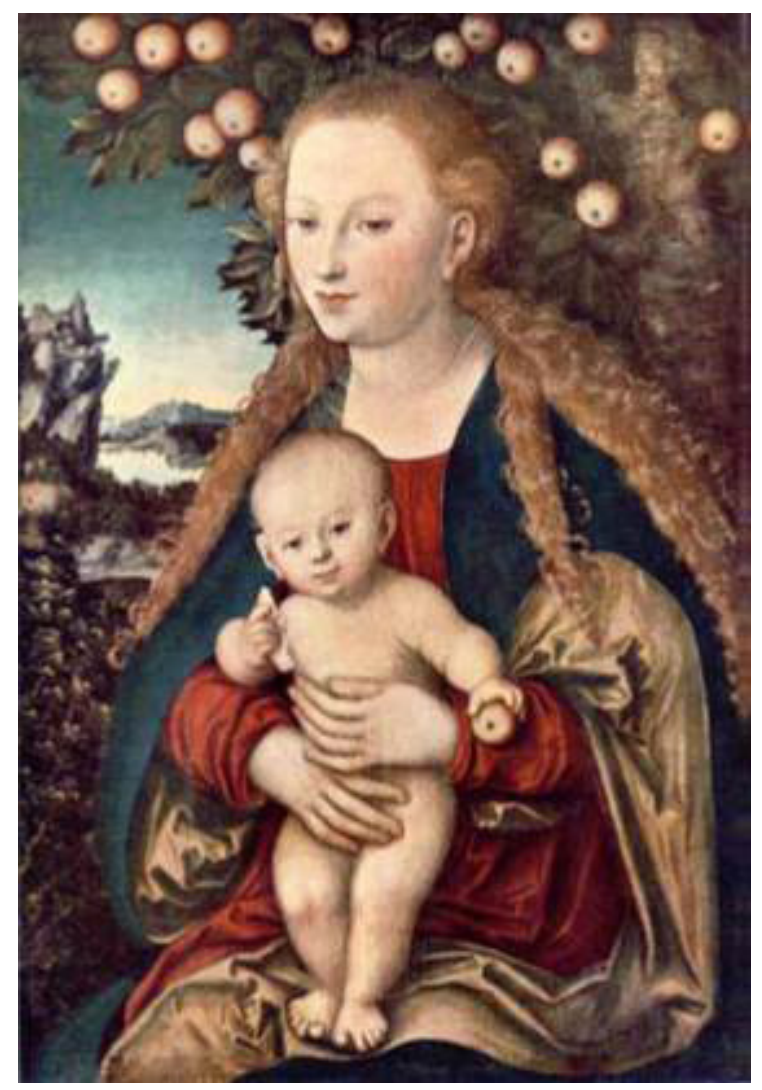

Fonte: Eremitério de São Petersburgo, Rússia
A escritora francesa Simone de Beauvoir (1970), precursora da frase "Não se nasce mulher, torna-se mulher", em seu livro "O Segundo Sexo" faz uma análise da condição da mulher. Para a autora, nas antigas criações do mundo um mesmo elemento tem se tornado frequente, uma encarnação, a um tempo, de macho e fêmea. Dizer que a mulher era o outro equivale a dizer que não existia entre os sexos uma relação de reciprocidade. A sociedade sempre foi masculina, e o poder político sempre esteve nas mãos dos homens, ou seja, a sociedade exaltava a superioridade masculina, o que se refletia na educação das moças, já que qualquer ato que fosse de desagrado ou servisse de ameaça à paz social era visto por todos com maus olhos.

O semelhante, o outro, que é também o mesmo, com quem se estabelecem relações recíprocas, é sempre para o homem um indivíduo do sexo masculino. Por isso, ele não partilhava com a mulher sua maneira de trabalhar e de pensar. A mulher sempre esteve destinada a ter dependência do homem, e jamais ser seu semelhante. Essa compreensão acorrentou culturalmente a mulher, moldando sua existência.

Apesar das diversas transformações provocadas com o surgimento e o desenvolvimento do capitalismo, as inúmeras culturas são predominantemente baseadas na supremacia masculina sobre as mulheres. As grandes revoluções do Século XVIII não revolucionaram o poder entre os sexos e não suprimiram a dominação e a violência nas relações com as mulheres. No século XIX, eram explícitos os padrões e condutas que o poder definia como desejáveis no comportamento feminino - trabalho e submissão.

Silva (2001, p.1) relata a situação de opressão e subordinação vivenciada pelas mulheres:

\footnotetext{
Várias foram as modificações sofridas na estrutura familiar, tomando por base a família do século passado e suas transformações, até chegar ao modelo da família contemporânea. A família era estruturada num regime patriarcal onde a mulher e os filhos deviam inteira submissão ao pai. (...) A família subjugada, sem direito a idéias e vontades próprias, era a forma de manter o equilíbrio social da época, que era voltado para a manutenção do patrimônio e a permanência desta no núcleo familiar formando cidadãos cuja consciência era atrelada aos mesmos valores de seus ancestrais. O pai, senhor supremo, encarregava-se de manter a família dentro dos
} 
padrões sociais. A ele competia julgar o certo e o errado, o futuro e o destino de seus filhos, sempre levando em conta as necessidades da família e nunca do indivíduo. (...) Toda essa repressão à personalidade própria do indivíduo trouxe à tona o desejo de liberdade, o desejo de amar e ser amado, o desejo de realização fosse pessoal ou profissional, desejos esses que sempre existiram, se não abertamente ao menos no intimo do individuo.

Durante muitos séculos, a mulher viveu apenas para o lar. Com o passar do tempo, as condições sociais do mundo foram transformadas, e as mulheres foram aos poucos tomando seu lugar na sociedade. Passaram, então, a travar as lutas necessárias pelo reconhecimento da igualdade, ganhando o espaço público e rompendo definitivamente a barreira do silêncio.

No início do século XX, no Brasil, havia uma clara divisão sexual do trabalho nas fábricas: as mulheres ocupavam as tarefas menos especializadas e mal remuneradas, e os cargos de direção cabiam aos homens. Devido à falta de legislação trabalhista, as trabalhadoras denunciavam à imprensa operária as péssimas condições de trabalho e higiene, o controle disciplinar a que elas eram submetidas em seus locais de trabalho. Nesse contexto, de forma inédita no Brasil, a Constituição de 1934 assegurou à mulher o direito de voto e da livre concorrência ao funcionalismo público de forma igualitária.

A partir da Primeira Guerra, evidenciou-se a tendência à presença da mulher nos setores primário, secundário e terciário da economia, ocupando não só o espaço rural, mas também o da indústria e o de serviços. Ao longo do século XX, as novas tecnologias de comunicação e mecanização das tarefas fizeram acontecer uma revolução administrativa, da qual a mulher participou, e a partir daí ela pôde ampliar seu espaço nesse ramo da economia, passando a fazer parte da força de trabalho, em nível de participação no mercado equiparável ao dos homens (QUELHAS, 2011).

Face à necessidade de produzir em igualdade com os homens, as mulheres passaram a assumir nova identificação, transformando seu modo de vestir e de se comportar. Começa a existir um novo modelo feminino. As mulheres percebem que face à grande competitividade organizacional, os métodos mais humanos de governar são mais eficientes, e co- meçam a utilizar um novo modo de governar, com mais objetividade, emoção e inteligência.

A partir da década de 60, várias leis melhoraram a figura da mulher, como a edição do Estatuto da Mulher Casada, que devolveu a plena capacidade à mulher, que passou a ter a condição de colaboradora e administradora na sociedade conjugal. Outro marco significativo foi a aprovação da Lei do Divórcio (1977), que substituiu a palavra desquite por separação judicial e, também, tornou facultativa a adoção do patronímico do marido e estendeu ao homem o direito de pedir pensão. A principal mudança ocorreu com a Constituição Federal de 1988, que instituiu o princípio da igualdade ao igualar homens e mulheres nos direitos e deveres e vedar qualquer tipo de preconceito e discriminação. Por isso é importante avaliar o crescimento da mulher na sociedade não apenas no âmbito profissional, mas dentro do contexto de democracia.

$\mathrm{O}$ que elas reivindicam hoje é serem reconhecidas como existentes ao mesmo título que os homens e não de sujeitar a existência à vida, o homem à sua animalidade. Uma perspectiva existencial permitiu-nos, pois, compreender como a situação biológica e econômica das hordas primitivas devia acarretar a supremacia dos machos (BEAUVOIR, 1970, p.86).

Nos últimos 150 anos, o movimento feminista tem sido responsável por diversas conquistas na vida da mulher, no entanto ainda há buscas por melhores condições e respostas eficazes. Hoje, o modo como cada mulher se coloca frente à sociedade se distancia cada vez mais do papel feminino exercido no século XIX; graças a sua influência ela vive nos dias atuais frente ao seu tempo, expondo-se às críticas e lutando para conquistar o espaço quase sempre acirrado.

\section{A inserção da mulher no atual mercado de trabalho}

A mulher do século XXI vem ganhando cada vez mais espaço no trabalho, na política, na sociedade e na economia, com o compromisso de manter o equilíbrio sem perder a sua feminilidade, perante uma nova forma de viver, pensar e agir.

Estudos a respeito da crescente participação da mulher no mercado de trabalho concluem que este está relacionado a fatores culturais, demográficos 
e econômicos. Há algumas décadas a porcentagem de mulheres economicamente ativas tem aumentado consideravelmente. Isso se deve também, entre outros fatores, aos movimentos políticos e sociais ocorridos no mundo entre as décadas de 60 e 70 . Essa mudança de padrões culturais impulsionou as mulheres a estudarem mais e a participarem do mercado de trabalho de forma consistente. Outro fator de grande relevância para a crescente participação das mulheres no mercado de trabalho refere-se à estagnação econômica, elevada inflação e mudanças na estrutura do emprego vividas pelo Brasil na década de 80 .

Os atributos denominados "femininos" começam a ser valorizados. As pessoas qualificadas como inovadoras e intuitivas estarão mais aptas para conquistarem os cargos de chefia e liderança. Calil (2000, p. 70) destaca que:

A partir de agora, o paradigma do empregado que as empresas buscam é pessoa criativa e flexível às mudanças rápidas que varrem o mundo todo, em detrimento da figura do profissional cartesiano tão afeito à produção em série, à hierarquia absoluta $\mathrm{e}$ à compartimentação de funções, pois para produzir mecanicamente informações ou tarefas, máquinas fazem isso infinitamente mais rápido e com mais eficiência. Hoje em dia, os departamentos de recursos humanos estão buscando uma qualidade que por muito tempo foi ridicularizada por ser considerada feminina demais: a intuição. Algo que as máquinas ainda são incapazes de produzir.

As mulheres se destacam em algumas habilidades, o que vem possibilitando sua inserção no mercado de trabalho, em especial, pela capacidade empreendedora e de encarar com seriedade os desafios que se apresentam a cada dia: motivação, capacidade de trabalhar em grupo, intuição, criatividade, administração de conflitos, organização, administração de recursos escassos, administração do tempo, atenção para o detalhe e simultaneidade.

Com essas características as mulheres estão conseguindo, cada vez mais, conciliar os trabalhos da vida pessoal com a profissional. O que antes era considerado um obstáculo, atualmente é considerado como um grande desafio. A participação da mulher no mundo dos negócios e a sua independência financeira vêm mudando a forma como os produtos e serviços são desenvolvidos e comercializados.
A mulher está cada vez mais assumindo cargos estratégicos nas organizações, além de atuar como administradora do lar e educadora dos filhos. Para Capelle (2004), as grandes transformações percebidas na sociedade refletem-se no campo organizacional, apontando para um cenário de intensa competição e discriminação, principalmente para o universo feminino, que absorve as responsabilidades profissionais, conciliando as responsabilidades também com a família. A conciliação entre vida profissional e vida familiar, principalmente em relação à dupla jornada e à maternidade, é fator de conflito vivenciado pelas mulheres, deixando clara a diferenciação da condição da mulher em relação ao homem no mercado de trabalho.

Nessa perspectiva, na opinião da autora, as diferenças entre o gênero feminino e o masculino são hierarquizadas de maneira diferente, e o trabalho da mulher acaba sendo colocado numa posição inferior ao trabalho masculino. Vários estudos evidenciam que o aumento da participação das mulheres no mercado de trabalho não correspondeu a uma diminuição da discriminação. Embora se tenha verificado mudanças importantes, a discriminação da mulher permanece, pois os homens continuam ocupando os mais altos cargos e ganhando maiores salários. Os trabalhos considerados mais formais e estáveis, principalmente vinculados a cargos de chefia, são normalmente ocupados por homens, enquanto os trabalhos com menores atribuições de responsabilidades, ou aqueles na função de atendimento, são relegados às mulheres.

A forma de desenvolvimento capitalista produziu historicamente uma vida cotidiana na qual o tempo que conta e que tem valor é aquele empregado na produção, aquele que gera mais valia. $\mathrm{O}$ período dedicado ao descanso, ao lazer, à reposição de energia, de se reconstituir física e mentalmente é aquele que sobra das atividades produtivas. O trabalho doméstico, base material de sustentação das necessidades cotidianas, é inteiramente destituído de valor social no sistema capitalista. Um trabalho considerado sem valor leva a uma situação em que o tempo empregado na sua realização não é medido nem visibilizado.

No entanto, após trinta anos de movimentos feministas, o perfil do mercado brasileiro apresenta mudanças relativas a gênero. Se, antes, os serviços 
domésticos eram realizados apenas pelas mulheres, hoje os homens também disputam esse mercado, uma necessidade imposta pela falta de qualificação. Por outro lado, é cada vez maior o número de mulheres que precisam trabalhar para sustentar sozinhas suas famílias e não têm com quem deixar seus filhos.

Mesmo em presença dessa circunstância de inferioridade, a partir da inclusão feminina no espaço organizacional as relações de trabalho ganharam novos significados, pois homens e mulheres passaram a concorrer por oportunidades de cargos, posições hierárquicas, destaque e reconhecimento profissional.

A participação das mulheres no mundo do trabalho impõe, também, sua presença nos espaços de luta política. Elas conquistaram o direito de participar dos sindicatos, na condição de filiadas, na luta por igualdade no trabalho; e no plano da participação política, o direito de votar e de serem votadas, na busca de seu pleno reconhecimento como mulheres e como cidadãs.

Assim, observando e fazendo uma análise histórica da evolução das mulheres no contexto organizacional, social e familiar, notamos uma dinâmica constante de desenvolvimento, crescimento e conquistas. Entretanto, com foco nas organizações, mediante a ascensão e o crescente aumento das mulheres no mercado profissional, surgiram novos tipos de contradições nos espaços de interação social. Em grande parte das organizações, a sua lógica é calcada em valores "masculinos", e tal lógica continua ainda a ser um obstáculo para as mulheres. Nesse contexto, as relações de gênero demandam discussão e análises.

\section{Considerações finais}

Ao longo do século XX, o movimento feminista passou por diferentes momentos. Assim como outros movimentos de minorias sociais, este se caracterizou no decorrer da história pela sua especificidade: a luta pela conquista dos direitos das mulheres.

Porém, o movimento feminista não visava só garantir a participação da mulher na sociedade de forma equivalente à do homem e conquistar a igualdade em todos os direitos. O movimento aborda, também, temas como o trabalho, a violência, a sexualidade, os estereótipos da mulher, entre outros, de forma única e revolucionária. "Uma vez que a opressão da mulher é a forma primordial e mais global de dominação, o movimento feminista trazia em si todo o potencial revolucionário das outras lutas" (GARAUDY, 1982, p. 68).

Nesse sentido, constatamos que nas últimas décadas o movimento pela "libertação das mulheres" obteve consideráveis ganhos sociais, políticos e econômicos, melhorando a situação de muitas mulheres. Concomitantemente, os movimentos feministas contribuíram fortemente para a análise cultural contemporânea.

Igualmente, as pesquisas antropológicas realizadas por teóricos do tema demonstraram que há uma enorme diversidade de condutas dos gêneros, embora houvesse uma aparente universalidade quanto à subordinação das mulheres, pois independentemente das tarefas a elas designadas em diferentes culturas, as mulheres eram consideradas inferiores aos homens.

Desse modo, as teorias feministas possibilitaram não só compreender as diferentes formas de construção da identidade social e individual da mulher, mas também refletir sobre as relações de gênero: como se criam, se transformam ou se mantêm os padrões de gênero na sociedade, ou seja, para além desse sujeito "mulher", universal, visualizando novos sujeitos.

Nesse contexto, a história evidencia que as primeiras conquistas específicas das mulheres se deram não só por meio da luta pela igualdade legal e contra as restrições dos seus direitos, mas também por meio da luta pela eliminação das barreiras que lhes impediam o desenvolvimento como pessoas. E, se assim foi, é porque aspiravam à substituição da dupla moral por um só valor e exigiam o direito ao voto, ao sufrágio universal, ao acesso à educação formal e à formação profissional.

Ao longo do tempo, a experiência demonstrou à sociedade e, em particular, às mulheres, que em qualquer situação, e desde que tenham oportunidades, a capacidade de desempenho delas é igual a dos homens. A evolução das mulheres no mundo do trabalho fez com que suas características fossem se alterando, e elas passaram a ocupar postos de trabalho tidos como masculinos. Além das dificuldades econômicas e da decorrente necessidade de contribuir para o orçamento familiar, a elevação do seu nível educacional e a redução do tamanho da família fize- 
ram da mulher um elemento fundamental no desenvolvimento das nações.

Constatamos que a mulher deixou de ser uma personagem passiva na sociedade familiar e social para ser um agente ativo, defensora de ações e argumentos em prol de sua postura: planejar, organizar, dirigir, controlar e realizar.

Portanto, é fundamental a compreensão de que a presença da mulher no ambiente organizacional modifica e transforma padrões, conceitos e crenças. Mas esse é um processo dinâmico que ainda se encontra em construção, no qual os papéis de homem e mulher estão sendo redefinidos de acordo com uma visão que considera os seres humanos em sua globalidade e os liberta de padrões rígidos de comportamento.

\section{Referências}

BEAUVOIR, S. O segundo sexo. 4.ed. São Paulo: Difusão Européia do Livro, 1970. p. 86.

BIBLIA. Edição de promessas. rev. cor. São Paulo: King’s Cross Publicações, 2004.

BUTLER, J. P. Problemas de gênero: feminismo e subversão da identidade. Estudos Feministas. Florianópolis, 2003. p.179-183.

CALÁS, M. B.; SMIRCICH, L. Do ponto de vista da mulher: abordagens em estudos organizacionais. In: CLEGG, S. R.; HARDY, C. Handbook de estudos organizacionais. São Paulo: Atlas, 1999. p.276-281.

CALIL, L. E. S. História do direito do trabalho da mulher: aspectos históricos /sociológicos do início da República ao final deste século. São Paulo: LTr, 2000. p.70.

CAPPELlE, M. C. A. et al. Uma análise da dinâmica do poder e das relações de gênero no espaço organizacional. RAE - Revista de Administração de Empresas. (Eletrônica) v.3. n. 2. Art. 22. jul./dez. 2004.

GARAUDY, R. Liberação da mulher, liberação humana. Rio de Janeiro, Zagar, 1982.

JAGGAR, A. M. Feminist philosophy. Boulder, CO: Westview Press. 2004.

MARX, K. Contribuição à crítica da economia política. São Paulo: Martins Fontes. 2003.

MURARO, R. M.; BOFF, L. Feminino e masculino: uma nova consciência para o encontro das diferenças. 3 ed. Rio de Janeiro: Sextante, 2002.

PRATAS, G. M. D. L. O feminino na arte medieval. Disponível em: <http:/www.spectrumgothic.com.br/goticohistoricodamulher $>$. Acesso em: maio de 2011.
QUELHAS, F. C. Mulheres executivas no mercado de trabalho. Disponível em: <http://www.excelenciaemgestao. org/Portals2>. Acesso em: maio de 2011.

SARDENBERG, C. M. B. Estudos feministas: esboço crítico. In: AMARAL, C. C. G. (Org.). Teoria e práxis dos enfoques de gênero. Salvador: REDOR, 2004.

SILVA, J. A. Curso de direito constitucional positivo. 18.ed. São Paulo: Malheiros Editores, 2000.

TONG, R. P. Feminist thougt. Boulder: Westview Press, 1998.

VIEIRA, C. M. D. Novo olhar sobre a mulher na administração de espaço, conquistas e desafios. Disponível em: <http://www.ethos.org.br-nordeste>. Acesso em: maio de 2011 .

Recebido em: 3 de maio de 2012 Aceito em: 17 de setembro de 2012 